\title{
Development of Construction and Repair Materials Used in Transport and Technological Machines Operating in the Arctic
}

\author{
Ekaterina Kosenko ${ }^{1}$, Natalia Baurova ${ }^{1,}{ }^{*}$, Vladimir Zorin ${ }^{1}$, and Alexander Konoplin ${ }^{1}$ \\ ${ }^{1}$ Moscow Automobile and Road Construction State Technical University (MADI), 125319, Moscow, \\ Leningradsky pr. 64, Russia
}

\begin{abstract}
Increasing the pace of development of the Arctic zone, among other tasks, requires the attraction of significant production resources to improve the transport network, in particular, road construction equipment and technological equipment. Extreme climatic conditions, including low air temperatures and strong winds, are features of the Arctic zone. In this regard, there is a need to form a methodological basis for the development of construction and repair materials for use in the Arctic. To solve this problem, based on the results of mechanical tests at temperatures of $+20^{\circ} \mathrm{C}$, $-30^{\circ} \mathrm{C}$ and $-50^{\circ} \mathrm{C}$, the possibility of using carbon fiber plastics with various types of hybrid matrices for the manufacture of mechanical engineering products operating in extreme conditions of the Arctic and the creation of reinforcing linings during their repair. The indicators of manufacturability during repairs under the conditions of constant exposure to negative temperatures using polymeric materials are considered.
\end{abstract}

\section{Introduction}

It is known that in the development of technological processes for the production and repair of equipment in the selection of construction and repair materials, the conditions in which this equipment will be used play an important role.

In the context of the growing pace of development of the Arctic zone, the development and implementation of modern, reliable technological methods for the production and repair of machines adapted to the conditions of the Arctic is one of the most important directions in the development of science and technology.

For the production of modern technology, a variety of structural materials are used, among which, due to the ability to create products with specified physical, mechanical, thermophysical and other properties, polymer composite materials (PCM) are widely used $[1,2]$.

The expansion of the use of PCM in various industries, including the automotive industry and road-building engineering, is hampered by the lack of awareness of engineering and scientific workers in matters of their strength, reliability and durability, including in the extreme conditions of the Arctic [3, 4].

${ }^{*}$ Corresponding author: nbaurova@mail.ru 
These properties of PCM are of particular importance, since they are less studied in comparison with the properties of such traditional structural materials as metals and their alloys $[5,6]$.

One of the areas of research on the problem of the use of PCM is the expansion of the temperature range of operation of products and structures made or restored using composites [7].

Among the modern methods of repairing machine parts, polymer technologies have recently been widely used [8]. This is due to the low labor intensity and cost of repair work, as well as the lack of the need to attract qualified specialists. However, there is no information in the technical literature about testing the product for manufacturability from the point of view of repair under the influence of negative temperatures (in the Arctic).

The nomenclature of technological operations when performing repairs of machine parts using polymer composite materials in conditions of negative temperatures is standard. However, in most technological operations there is a significant reduction in the range of materials, devices and equipment [9].

In order to control changes in quality indicators, it is proposed to use an integral correction factor (1), which takes into account the effect of many factors that can affect both negatively and positively on the desired value.

$$
K=k_{1} \cdot k_{2} \cdot k_{3} \cdot \ldots \cdot k_{i}
$$

where $k_{1} \ldots k_{i}$ are coefficients that take into account the quality loss at each individual technological operation. The indexes of the $k$ coefficients are given in accordance with the numbers of the operations of the repair technological process.

So, for five technological operations used in the repair of exhaust systems of road construction machines using PCM, based on experimental studies, taking into account the previously found optimal technological modes, the values of the property preservation coefficients were determined: surface preparation $\left(k_{1}=0.9\right)$; preparation of PCM $\left(k_{2}=0.85\right)$; application of PCM to the surface to be restored $\left(k_{3}=1\right)$; curing of PCM $\left(k_{4}=0.95\right)$; quality control $\left(k_{5}=1\right)$.

Substituting the values of the property conservation coefficients found experimentally in expression (1), we observe a drop in quality by almost $30 \%$. In the absence of additional testing of the technological process for climatic adaptability, quality losses will be observed not only at the stages of surface preparation, application and curing of PCM, but at all five stages.

The greatest quality losses occur during the PCM preparation operation. This is primarily due to the fact that it is impossible to accurately weigh the components in an open space at subzero temperatures. The viscosity of the glue components increases at negative temperatures, which leads to the fact that part of the material remains on the walls and this is the reason for the violation of the dosage of the components.

The quantitative indicators of manufacturability include labor intensity, material consumption, energy consumption. When assessing climatic manufacturability, as well as when assessing the main quantitative indicators of manufacturability, a comparison of a new repair technology is made with a certain conditional standard, which is usually taken as a similar technical process, which is usually called the base (or reference). This approach allows the use of uniform indicators (K coefficients), which allow you to take into account changes in comparison with the base value, for example, in terms of cost or applicability.

To date, there are no comprehensive studies that allow us to determine the changes in the set of mechanical properties of PCM during the transition to the region of negative temperatures. 
The purpose of this study is to determine the changes in the physical and mechanical properties of structural and repair materials during their operation in the extreme conditions of the Arctic.

\section{Materials and methods of research}

The addition of components (modifiers) to the PCM matrix that retain their viscoelastic state after forming the product and at the entire stage of its operation allows not only to increase the deformation and strength properties, but also to ensure the stability of mechanical properties during the transition to negative temperatures (up to $-50^{\circ} \mathrm{C}$ ).

Based on the analysis of the curing mechanism and manufacturability of using various polymeric materials $[10,11]$ as viscoelastic components of PCM (modifiers), the following were selected: technical wax, anaerobic and organosilicon polymeric materials. These viscoelastic components form a hybrid PCM matrix with the main binder material.

A biaxial carbon fabric based on T300 carbon fiber was selected as a reinforcing material for PCM samples with various types of hybrid matrices. As a binder, an epoxy resin of the Elan-Tech EC 57 brand was used with a hardener W61 (in the proportion of 100:16 by weight), which provides a viability time of the resin + hardener compound of 70 ... 80 minutes.

To perform mechanical tests using the prepreg technology, 4 series of flat rectangular carbon fiber samples with a size of 20x250x1.3 were produced (for PCM with technical wax in the matrix: $20 \times 250 \times 3.4)$ : a control sample without viscoelastic components (1 series), with anaerobic polymer material Loctite 638 ( 2 series), with organosilicon polymer material Unisil-9628 (3 series) and with technical wax in the matrix (4 series) [12, 13].

Each series of samples was made in three sets: the 1st set of samples was not exposed to negative temperatures and was stored at a temperature of $t_{1}=20 \pm 2^{\circ} \mathrm{C}$; The 2 nd set of samples was kept in a PozisFH-258-1 freezer at a temperature of $\mathrm{t}_{2}=-30^{\circ} \mathrm{C}$ for 60 days. The third set of samples was kept in a LOIP FT-311-80 liquid cryothermostat at a temperature of $\mathrm{t}_{3}=-50^{\circ} \mathrm{C}$ for 30 days. In the cryostat, medical ethanol was used as a working fluid (heat carrier), and air was used in the freezer.

The tests of the samples were carried out in order to determine the tensile strength using a machine for testing structural materials "UTS 110M-50" and using the temperature test system "STI TS 3" (for samples subjected to preliminary exposure at negative temperatures). Before testing at temperatures $\mathrm{t}_{2}=-30^{\circ} \mathrm{C}$ and $\mathrm{t}_{3}=-50^{\circ} \mathrm{C}$, the samples were kept at the corresponding temperatures for 60 minutes. The test speed was $\mathrm{V}=2 \mathrm{~mm} / \mathrm{min}$ for all samples.

\section{Discussion of research results}

The main purpose of the tests was to determine the loss of strength $\Delta$ and deformation properties (elongation at failure $\Delta \delta$ ) associated with the influence of negative temperatures $(2-5)$.

$$
\begin{aligned}
& \Delta \sigma^{-30}=\sigma^{+20}-\sigma^{-30} \\
& \Delta \sigma^{-50}=\sigma^{+20}-\sigma^{-50}
\end{aligned}
$$

where $\sigma^{+20}, \sigma^{-30}, \sigma^{-50}$ is the strength of $\mathrm{PCM}$ at a temperature of $20^{\circ} \mathrm{C},-30^{\circ} \mathrm{C},-50^{\circ} \mathrm{C}$, respectively.

$$
\Delta \delta^{-30}=\delta^{+20}-\delta^{30}
$$




$$
\Delta \delta^{-50}=\delta^{+20}-\delta^{50}
$$

where $\delta^{+20}, \delta^{-30}, \delta^{50}$ is the relative elongation of the PCM upon failure at a temperature of $20^{\circ} \mathrm{C},-30^{\circ} \mathrm{C},-50^{\circ} \mathrm{C}$, respectively

The test results are presented in tables 1 and 2 .

With a decrease in temperature, the destruction of carbon fiber plastics of all series occurs at lower stresses and is accompanied by intense cracking of the surface.

Table 1. Average values of mechanical properties of carbon fiber plastics with different types of hybrid matrices during tensile testing

\begin{tabular}{|c|c|c|c|c|c|c|}
\hline \multirow[t]{2}{*}{ Matrix modifier type } & \multirow{2}{*}{$\begin{array}{l}\text { Reinforcing } \\
\text { material } \\
\text { type }\end{array}$} & \multicolumn{5}{|c|}{$\begin{array}{l}\text { Ultimate strength } \sigma, \mathrm{MPa} \text { at the holding and test } \\
\text { temperature, }{ }^{\circ} \mathrm{C}\end{array}$} \\
\hline & & +20 & -30 & $\Delta \sigma^{-30}$ & -50 & $\Delta \sigma^{-50}$ \\
\hline without modifier & \multirow{4}{*}{$\begin{array}{l}\text { Carbon } \\
\text { fabric }\end{array}$} & 1800 & 1360 & 440 & 1270 & 530 \\
\hline anaerobic polymer material & & 1900 & 1370 & 530 & 1274 & 626 \\
\hline $\begin{array}{l}\text { organosilicone polymer } \\
\text { material }\end{array}$ & & 1290 & 1160 & 130 & 1230 & 60 \\
\hline technical wax ${ }^{\mathrm{a}}$ & & 560 & 410 & 150 & 140 & 420 \\
\hline
\end{tabular}

${ }^{a}$ When comparing the mechanical properties of carbon fiber plastics with different types of hybrid matrices, it is necessary to make an adjustment for the scale factor of the samples (samples of carbon fiber with technical wax in the matrix with an equal width had a thickness of 2.6 times larger than the other samples).

Table 2. Average values of relative elongation in the destruction of carbon fiber plastics with different types of hybrid matrices

\begin{tabular}{|c|c|c|c|c|c|c|}
\hline \multirow[t]{2}{*}{ Matrix modifier type } & \multirow{2}{*}{$\begin{array}{l}\text { Reinforcing } \\
\text { material } \\
\text { type }\end{array}$} & \multicolumn{5}{|c|}{$\begin{array}{l}\text { Elongation of specimens at fracture } \delta, \% \\
\text { at the temperature of holding and testing, }{ }^{\circ} \mathrm{C}\end{array}$} \\
\hline & & +20 & -30 & $\Delta \delta^{-30}$ & -50 & $\Delta \delta^{-50}$ \\
\hline without modifier & \multirow{4}{*}{$\begin{array}{l}\text { Carbon } \\
\text { fabric }\end{array}$} & 5,3 & 4,9 & 0,4 & 4,5 & 0,8 \\
\hline anaerobic polymer material & & 5,7 & 5,6 & 0,1 & 4,6 & 1,1 \\
\hline $\begin{array}{l}\text { organosilicone polymer } \\
\text { material }\end{array}$ & & 5,5 & 5 & 0,5 & 4,7 & 0,8 \\
\hline technical wax ${ }^{\mathrm{a}}$ & & 7,1 & 4,4 & 2,7 & 4 & 3,1 \\
\hline
\end{tabular}

Carbon fiber with an anaerobic polymer material in the hybrid matrix at the transition to the region of negative temperatures has the best tensile strength (compared to the samples of the other series), the maximum value of the elongation at failure at a temperature of $\mathrm{t}_{2}=-$ $30^{\circ} \mathrm{C}$, and a relatively high value of this indicator at $\mathrm{t}_{3}=-50^{\circ} \mathrm{C}(2 \%$ higher compared to carbon fiber without viscoelastic matrix modifiers).

Tests of carbon plastics with an organosilicon polymer material in a hybrid matrix showed a slight decrease in the value of tensile strength (by $10 \%$ and $5 \%$ at temperatures $t_{2}$ $=-30^{\circ} \mathrm{C}$ and $\mathrm{t}_{3}=-50^{\circ} \mathrm{C}$, respectively), while for this series of samples, the maximum value (in comparison with the samples of the other series) of the relative elongation at fracture at a temperature $\mathrm{t} 3=-50^{\circ} \mathrm{C}(4 \%$ higher compared to carbon plastics without viscoelastic components in the matrix) is noted.

The samples of carbon fiber with technical wax in the hybrid matrix at a positive temperature have the maximum $(20 \ldots .25 \%$ higher $)$ value of the relative elongation at 
fracture compared to the samples of the other series. However, in the region of negative temperatures, this type of samples showed the greatest intensity of reduction and the worst values of both deformation and strength properties.

The choice of the optimal type of viscoelastic components can be carried out using the ideal point method using two criteria, for example: the loss of strength after exposure and testing at a temperature of $-30^{\circ} \mathrm{C}$, the values of which should be minimal, and the integral technological criterion, the values of which should also tend to a minimum.

As an optimized parameter, the type of viscoelastic component is used, which makes it possible to provide the highest values of the mechanical strength of the PCM after prolonged exposure to negative temperatures and minimal labor intensity of their application [6].

$$
R=\sqrt{\left(\Delta \sigma_{i}-\Delta \sigma_{0}\right)^{2}+\left(\psi_{i}-\psi_{0}\right)^{2}} \rightarrow \min
$$

where $\mathrm{R}$ is the distance to the ideal center; $\Delta \sigma_{i}$ and $\Delta \sigma_{0^{-}}$strength losses after exposure to negative temperatures of the considered options of the modifier and the ideal center; $\psi_{i}$ and $\psi_{0}$ are the total values of costs in the manufacture and application of the considered options for modifiers and the ideal center.

During the destruction of PCMs with viscoelastic components in the matrix, the nucleation and growth of a transverse macroscopic crack (normal separation crack), the nucleation and growth of a sliding crack are observed. Transverse macroscopic cracks and sliding cracks in the PCMs body form a kind of system of chaotically or in a certain way oriented cracks, the mutual influence of which is of considerable interest in assessing the mechanism of destruction of PCM with different types of hybrid matrices.

Thus, to realize the strength potential of PCMs with different types of hybrid matrices, the location of viscoelastic components must be performed according to the specified schemes. The scheme of location of viscoelastic components in the PCM matrix is developed based on the analysis of the active loads (magnitude, direction, nature of loads) and the stress-strain state of the composite.

The optimal location scheme for viscoelastic components in the matrix can be selected based on the solution of the combinatorial optimization problem. At the same time, it is necessary to take into account the anisotropy of the properties of the composite when ensuring the maximum set values of the deformation and strength properties in different directions of the action of loads. Thus, the objective function of the resulting multi-criteria problem will be represented by several expressions (7):

$$
\begin{gathered}
f_{1}\left(x_{1}, x_{2}, \ldots, x_{n}\right) \rightarrow \text { max } \\
f_{2}\left(x_{1}, x_{2}, \ldots, x_{n}\right) \rightarrow \text { max }, \\
\ldots \ldots \ldots \ldots \ldots \ldots \ldots \ldots \ldots \\
f_{m}\left(x_{1}, x_{2}, \ldots, x_{n}\right) \rightarrow \text { max } .
\end{gathered}
$$

where, $f_{1}, f_{2}, \ldots, f_{m}$ are the objective functions for optimizing the choice of the location scheme for viscoelastic components in the hybrid matrix, which characterize the set of properties $\left(x_{1}, x_{2}, \ldots, x_{n}\right)$ of structures in the directions of loads from 1 to $\mathrm{m}$, in other words, the number of target functions is equal to a given number of directions of action of loads on the structure.

The argument of the objective functions is the vector of parameters $\mathrm{X}=\left[x_{1}, x_{2}, \ldots, x_{n}\right]^{\mathrm{T}}$, which characterizes the set of mechanical properties of the structure of a product designed from a PCM with a hybrid matrix. The task of multicriteria optimization is to determine such a vector of parameters $\mathrm{X}^{*}=\left[x_{1}{ }_{1}, x^{*}, \ldots, x_{n}\right]^{\mathrm{T}}$, the values of which determine the maximum value of the objective functions $f^{*}, \ldots, f^{*}{ }_{m}$. 
When solving a multicriteria problem, it becomes necessary to maintain a balance between all objective functions, since maximizing one of them can lead to a deterioration in the values of the remaining functions. For this purpose, we introduce restrictions on the vector space of objective functions and represent them in the form of expressions (8):

$$
\begin{gathered}
x_{1}{ }^{(\min )} \leq x_{1} \leq x_{1}{ }^{(\max )}, \\
x_{2}{ }^{(\min )} \leq x_{2} \leq x_{2}{ }^{(\max )}, \\
\ldots \ldots \ldots \ldots \ldots \ldots \ldots \ldots . \ldots \ldots \ldots \ldots \ldots \ldots \\
x_{n}{ }^{(\min )} \leq x_{n} \leq x_{n}{ }^{(\max )} .
\end{gathered}
$$

As additional restrictions when solving a multicriteria optimization problem, the following can be taken: the mass of a PCM structure with a given location scheme for viscoelastic components in the matrix $m\left(x^{*}{ }_{1}, x^{*}{ }_{2}, \ldots, x^{*}{ }_{n}, f^{*}{ }_{1}, \ldots, f^{*}{ }_{m}\right) \leq m_{p e r}$, where $m_{p e r}$ is the permissible mass of a composite structure; the cost of manufacturing the structure $C\left(x_{1}^{*}, x_{2}^{*}, \ldots, x_{n}^{*}, f^{*}, \ldots, f^{*}{ }_{m}\right) \leq C_{p e r}$, where $C_{p e r}$ is the permissible cost price of manufacturing a structure from a composite with a given location scheme for viscoelastic components in the matrix; $L I\left(x^{*}, x^{*}, \ldots, x^{*}{ }_{n}, f^{*}, \ldots, f^{*}{ }_{m}\right) \leq L I_{p e r}$ labor intensity of manufacturing a structure from PCM with various types of hybrid matrices, where $L I_{p e r}$ is the permissible labor intensity of manufacturing a structure from PCM with a given scheme for the location of viscoelastic components in the matrix.

Figure 1 shows the algorithm for selecting viscoelastic components and their location schemes in the PCM structure.

\section{Conclusions}

As a result of the studies, it was found that with prolonged exposure to negative temperatures on PCMs with various types of hybrid matrices, the strength decreases to the least extent when using anaerobic (Loctite 638) and organosilicon (Unisil-9628) materials in the matrix. The lowest labor input associated with the manufacture and application of the modifier to the surface of the reinforcing filler was obtained using wax as a viscoelastic component of the hybrid PCM matrix.

The requirement of climatic adaptability will be met only if adequate replacements of materials and technological modes are found, the use of which will preserve not only standard repair technologies, but also the quality and timing of repair work. As a result of the conducted research, it is proposed to use a new indicator, which is called climate adaptability in the work. This indicator allows us to take into account the influence of climatic conditions on the quality of technological operations.

The material was prepared within the framework of scientific research under the project №FSFM2020-0011, experimental research using the equipment of the MADI Shared Use Center. 


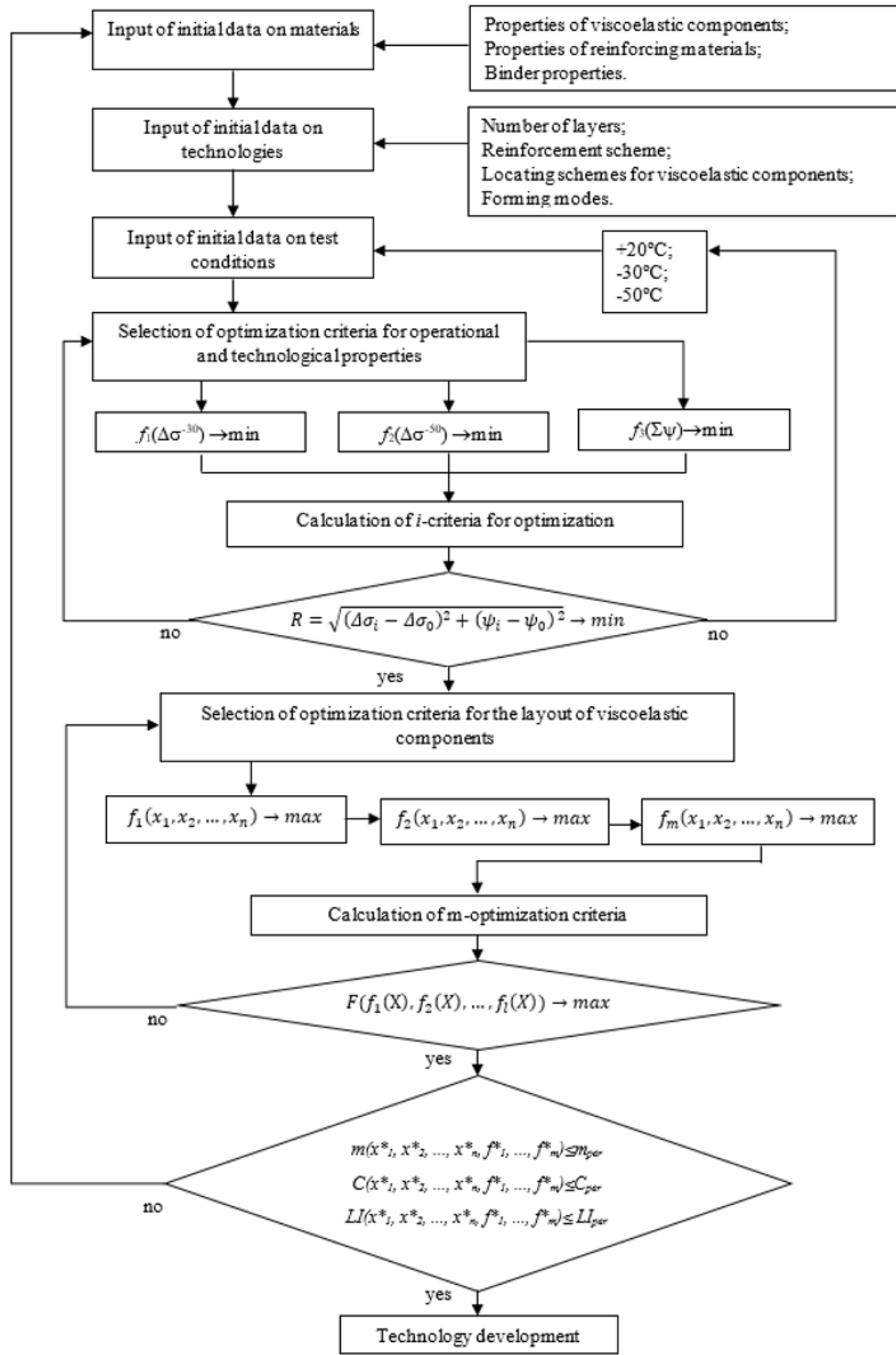

Fig. 1. Algorithm for the selection of the viscoelastic components of the hybrid matrix and its location scheme 


\section{References}

1. Malysheva G.V., Shimina Y.Y. Influence of preparation technology on carbon-fibercomposite component composition. Fibre Chemistry, v. 46 (4). pp. 237-240. (2014).

2. Ryakhovsskii O.A., Malysheva G.V., Vorobev A.N. Method for reaching airtightness of the joint between the casing of an impeller pump and its cover. Russian Metallurgy, v. 13. pp. 1312-1316. (2016).

3. Borodulin A.S., Marycheva A.N., Malysheva G.V. Simulation of impregnation kinetics of fabric fillers in the production of fiberglass articles. Glass Physics and Chemistry, v. 41(6). pp. 660-664. (2015).

4. Malysheva G.V., Shablygin M.V., Guzeva T.A. Method for assessing aramide fiber microstructure features. Fibre Chemistry, v. 47 (2). pp. 85-88. (2015).

5. Nelyub V.A. Method for assessing the chemical reaction between carbon fibre and epoxide binder. Fibre Chemistry, v. 47 (1). pp. 40-42. (2015).

6. Chen Ya., Gorodeetskii M.A., Nelyub V.A., Malysheva G.V. Algorithm for the optimmizaation of the technological conditions of forming epoxy-matrix-based composiites. Russian Metallurgy, v. 13. pp. 1369-1372. (2019).

7. Nelyub V.A., Gorberg B.L., Grishin M.V., Berlin A.A., \& Malysheva G.V. Properties and technology of applying metal coatings to carbon tape. Fibre Chemistry, v. 50 (6). pp. 524-527. (2019).

8. Rudskoi A.I., Baurova N.I. Technological heredity during the production and operation of structural materials. Russian Metallurgy, v. 13. pp. 1378-1383. (2019).

9. Konoplin A.Yu., Baurova N.I. Hardness of the near-weld zone during contact spot welding of steels using an adhesive-weld technology. Russian Metallurgy, v. 13. pp. 1308-1311. (2016).

10. Kobets L.P., Borodulin A.S., Malysheva G.V. Study of microcapillary impregnation of carbon fiber by epoxy binder. Fibre Chemistry, v. 48 (4). pp. 311-315. (2016).

11. Gorodetskii M.A., Nelyub V.A., Malysheva G.V., Shaulov A.Y., Berlin A.A. Technology of forming and the properties of reinforced composites based on an inorganic binder. Russian Metallurgy, v. 13. pp.1195-1198. (2018).

12. Kosenko E.A., Baurova N.I., Zorin V.A. Service properties of composites with various types of hybrid matrices. Russian Metallurgy (Metally), v. 13, pp. 1526-1530. (2020).

13. Baurova N.I., Zorin V.A., Prikhodko V.M. Determination of the synergetic effect of the damage accumulation process in polymer materials using catastrophe theory. Theoretical Foundations of Chemical Engineering, v. 50 (1). pp.119-125. (2016). 